\title{
The Quality and Strategy of Leading Cadres to Deal with the Pressure of Network Public Opinion
}

\author{
Yongguang $\mathrm{Yu}^{*}$
}

\author{
School of Environmental and Chemical Engineering, Jiangsu University of Science and Technology, Jiangsu \\ Province, PR China \\ ${ }^{*}$ Corresponding author. Email: 46897204@qq.com
}

\begin{abstract}
In the Internet age, the traditional discourse system has changed greatly, and is with a large transformation from the official media to official media and self-media coexistence. The changes in public discourse systems also make the discourse power structure reassigned. The openness, virtuality, spontaneity, convenience, vitality and interactivity of the Internet have increased the difficulty for leading cadres to respond to public opinion, and also puts forward higher requirements on the response capabilities of leading cadres, which calls for strength of facing and dealing with public opinion with flexibility and through scientific analysis and systematical management; there are also some other key requirements for cadres to fulfill the mission efficiently:mechanism establishment, solid foundation; willing to try, being good at monitoring, learning, and concluding, together with capability to respond timely and scientifically.
\end{abstract}

Keywords: Leading cadres, Network public opinion, Coping strategies.

\section{FOREWORD}

With the rapid development of the Internet globally, the network media has been recognized as the "fourth media" after newspapers, radio, and television [1], and has become one of the main carriers reflecting the customer's opinion. Network public opinion is based on the network media as the information propagation platform. It refers to the views, attitudes, cognition, emotions, and behaviors held by the people on government management and real-world society under certain social conditions. It is defined by the fast diffusing speed, large participation ratio and high attention degree. Correctly responding to network public opinion is closely related to social situation, stability, the image of the party and the government, just as mentioned by General Secretary Xi Jinping, the "Internet has become the main battlefield". In today's social public opinion, the generation, fermentation, and transmission mechanism of network public opinion continuously changes, and it has confronted every cadre with how to maintain the government's credibility and voice, while improve network response capability and level.

\section{REASONS FOR THE PUBLIC OPINION PRESSURE ON LEADING CADRES UNDER THE INTERNET BACKGROUND}

With the arrival of the third scientific and technological revolution represented by computer and Internet technology, it has not only greatly promoted the progress of human society in political, economic and cultural fields, but also significantly changed people's work, life, entertainment and even way to think. In the face of the arrival of the Internet era, each of us, especially the leading cadres at all levels can't avoid avoiding it. It should be due to the situation, the situation, the situation, take the initiative, analyze the cause of network public opinion, change pressure For the opportunity to make the Internet, the Internet has become a new bond that connects the government and the people's masses, close the government and the people.

\subsection{The Openness and Virtuality of the Internet Makes it Difficult to Control Public Opinion}

According to the China Internet Information Center (CNNIC), the 45th "China Internet Development Statistics Statistics Statistical Report" shows that as for June 2020, the number of netizen reached 914 million, 
and the Internet coverage has reached $64.5 \%$, and $99 \%$ are mobile users, which amounts to 900 million, China has entered the mobile interconnection era. It enables the netizen to record and share their own life online as public opinion. With the mobile interconnect, everyone can participate, make a sound, the openness of the Internet makes esay access to the information for netizen, no matter where they come from, they can express themselves. Feelings, views and attitudes are expressed through the Internet platform. At the same time, the characteristics of the virtuality of "Network Society" make network public opinion in value delivery, interest claims, etc., makes it difficult for the relevant departments of the government to pursue the rumors and fake news,.

\subsection{The Real-time and Convenience of the Internet, Leaves a Short Time to Respond to Public Opinion}

Compared with traditional media, in the self-media era, one only needs to copy, paste or forward, and information can be re-propagated. News event can be instantly attracted tens of millions of people, receiving millions of comments, which can't be imagined in the traditional media era. At the same time, the "Notice on Further Public Inaction in Government Affairs Office" in the General Office of the State Council clearly requires a fast response to a particular major emergency, and promptly sounds in time, with a press conference held within 24 hours, which invisibly brings huge work pressure to the leading cadres' disposal.

\subsection{The Vividness and Interaction of the Internet Makes it more Difficult to Monitor Public Opinion}

Network public opinion can be displayed on the Internet, with the characteristics of viewability, fun, entertaining, etc., which is easy to attract people. At the same time, everyone can express their own insights on the Internet platform, which generates point of collision, and increases the internal power of public opinion. In addition, the central communication status of the Internet, traditional media (such as television, broadcasting, newspapers, etc.) is overwhelming, due to the existence of circular culture, network public opinion is very easy to be wrapped in some so-called network celebrities. It easily arise huge waves and the incident may continues to ferment, deepen, and becomes difficult to predict, therefore, it would be difficlut for leading cadres to conduct effective guidance.

\section{THE CAPABILITIES THAT LEADING CADRES SHOULD ACQUIRE TO DEAL WITH THE PRESSURE OF PUBLIC OPINION UNDER THE INTERNET BACKGROUND}

Gicen the vigorous development of the Internet public opinion expression platform, some leading cadres consider network public opinion as a disaster, and are full of fear and hostile attitude, or consider the official media as the authority, comments on the Internet platform is mostly anecdotal. "The dimerits overweigh the merits." The deviation of understanding reveals that some leading cadres needs to be strengthened.

\subsection{Leading Cadres should have the Courage to Face the Public Opinion}

The courage a lofty moral quality. It is full of uncertainty or even dangers when facing the public opinions, but as today's network appeal has become increasingly unity, the leading cadres should avoid ignorance or detoring, and bear all the due responsibilities. The first step of handling public opinion is "Being fast", and facing the public opinion is as the premise and foundation, only by doing so can cadres better inspire the staff around in response to public opinion.

\subsection{Leading Cadres should be Calm and Confident to Respond to the Public Opinion}

Deliberation is a judgment, decision-making capacity and execution capability, a symbol of will, quality, and realm. Responding with calmness and control can make the it more reliable and meaningful. Therefore, the leading cadres should act calmly, in order to maintain a clearness, a sense of reason, of reason, so as grasp every each detail of the public opinion, and do thing right.

\subsection{Leading Cadres should be Sensitive with Public Opinion}

Sensibility is an external capability that one observes environment, others, discovery, and make rapid judgment, it is a logic superior ability based on the facts. Only by having a clear autumn, seeing ignorance, through the insight of the essence can the leading cadres stand high, think deeply, see far, and act accurately. Therefore, the leading cadres should equipped themselves with a sensitive vision.

\subsection{Leading Cadres should Judge and Prepare for Public Opinion Crisis}

The judgment is based on the pre-knowledge accumulation and experience summary. Through the thorough thinking, systematic analysis, and recognition 
of whether the object has certain attributes, the judgment is an important standard of strong thinking ability, and it reveals how individuals can think quickly, decisively, and accurately in the critical situations. The fermentation after the occurrence of online public opinion spreads fast beyong imagination. Therefore, preparation for a wellrounded and accurate judgment on the nature, characteristics and evolution of public opinion, is the premise for public opinion guidance. It is an important embodiment for cadres to handle.

\subsection{Leading Cadres should be Flexible to Deal with Public Opinion}

The resilience is the response made by people in the external changing matters, and the leading cadres must acquire such capabilities for decision-making, advancement implementation, and strengthen supervision. The ever-changing of online public opinion is an isolated incident that may involve more deep-level issues, causing a broader discussion, so in the face of miscellaneous network public opinion, leading cadres should have acumen and flexible force to deal with the radom changes, and pave way for the subsequent guidance,

\section{STRATEGIES AGAINST PUBLIC OPINION PRESSURES UNDER THE INTERNET FOR LEADING CADRES}

Several key factors play vital roles in dealing with online public opinions, such as transmissiblity determines influence, voice determines dominance, efficience determines effectiveness and transparency determines reputation.[2]Leading cadres should take the initiative, be flexible, scientific, and reliable, avoid bugs , demerits and promote efficiency, so as to obtain support and trust from public.

\subsection{Raise Awareness and Plan Systematically}

In recent years, the Internet has become the main battlefield for public opinion expression. Compared with traditional public opinion, it is characterisized by sudden, interactive, diversity and deviation factors, and calls for effective responses and coordinative promotion from the leading cadres. First, we must attach great importance to the recognition. Network public opinion as a very complex job, needs to mobilize many resources, coordinate multi-party relationships and establish a solid foundation before time. Second, it is necessary to use systematic thinking from the macro level to strengthen the top floor design of network public opinion events and respond to network public opinion events.

\subsection{Establish a Mechanism to Lay a Solid Foundation}

The perfect working mechanism is to form a sense of public opinion to ensure the basis of high-efficiency response. One is to coordinate and divide properly. Perple consider it as a whole after the public opinion crisie occurs, no matter where the problem comes. Therefore, everyone should cooperate together, work together, ensuring will be no other crisis, so as to lead public opinion to the right direction. The second is to implement the level-to-level management. In recent years, many cases of sensitive and complex public opinions have emerged in the basic units, implementation of grade and responsibility management helps to strengthen the targetedness of the public opinion, reducing the working pressure of the superior sector, and also helps to establish the first tier protection. The third is to do a good personnel training and provide necessary guarantees. Providing that the basic staff should be lack of sufficient experience, fiscial funds and support in public opinion, leading cadres are obliged to assist them and provide the necessary material guarantee.

\subsection{Experiment and Monitor}

Internet public opinion bears down menacingly, and the risk should be considered in advance. Leading cadres must be courageous to try new technical means, do a good job in the monitoring, warning and research of online public opinion. First, with today's technical means, semantic analysis, keyword extraction and tendency analysis are available and have reached a high accuracy, which greatly saves people's energy, and promotes the efficiency of locating public opinion sources. Second, current technical means can detect network public opinion event hits, reading rate, forwarding rate, recovery rate and positive or negative comment rate, thus providing assistance for monitoring. Finally, people can be inspired and creative on the basis of the machine development, and base on the relevant early warning standards, formulate the warning level of public opinion response, proposing the corresponding disposal, so as to ensure promptness, efficiency and accuracy.

\subsection{Good at Learning, Grasp the Law}

The generation, development, evolution of online public opinion has its characteristics and form a range of rules. It is important to study and grasp these features and rules, which is very important for leading cadres in public opinion. First of all, leading cadres should strengthen the learning of relevant documents of public opinion, clarify the specific requirements of network public opinion responses, and know the centralized field of network publicity hotspots, and identify the distribution law. Second, leading cadres should strengthen the research on online public opinion, as of March 2020, China's 29-year- 
old netizen has accounted for $52.4 \%$ of all netizen, and youth networkers have become the main body of the network. Therefore, research on the young netizen of their physiological characteristics such as living environment, network thinking, language system, behavioral habits is beneficial to grasp the evolution laws of network public opinion. Again, we must raise awareness of network public opinion, development, and evolve all aspects . In general, the development of online public opinion is featured with "spread, gather, hot discussion, epidemics, decay" six stages, each stage has the law, it is necessary to strengthen the understanding and research of such laws. Finally, leading cadres must be able to apply various media tools, and strengthen research on the communication characteristics of new network platforms. In recent years, with the media platform, the audio site has become the source of the new network public opinion, and the research of these platform sites will help lead cadres to enhance the ability to respond to public opinion.

\subsection{Timely Response, Scientific Response}

Online public opinion communication has the first sound effect. Whoever makes the first sound on the Internet has the initiative of public opinion [3]. On the contrary, the longer the public opinion stays, the more contradictions will be involved and the more difficult it will be to deal with. However, early response does not mean blind response, otherwise it may cause secondary damage to public opinion. In the process of responding to online public opinions, we should master some scientific principles, methods and skills so as to get twice the result with half the effort. First, we should make adequate preparations. Leading cadres should first have a clear understanding of the data, personnel and basic facts involved in public opinion, and make a basic judgment on the concerns and appeals of the public, which is the first step in responding to public opinion. Second, seek truth from facts. Especially in the highly developed Internet information today, any concealment, deception and exaggeration of public opinion response may be amplified by the Internet again, resulting in the passive response of public opinion. Third, we must seize high ground. We can take advantage of our own "two micro ends" to seize the opportunity. We can first explain the basic facts and the measures taken, and then gradually restore the truth by rolling broadcast as the investigation goes deeper. Fourth, we should establish authority. In the face of the surging online public opinion, we can actively invite the mainstream media to actively assist, give full play to the role of the "anchor in the sea" in the battlefield, firmly grasp the initiative and leadership of public opinion guidance, and prevent non-mainstream media or even foreign media from stealing the limelight.

\subsection{Combining Possible Sources to Strengthen Guidance}

Any unit and individual are inferior in front of a massive public opinion crisis, we must build a united front, and guide netizen to think scientifically and act rationally. First, make friends at a wide range. Not only should be strengthened with mainstream media, but also cooperate with network celebrities, opinion leaders in the Internet, regularly listen to their recommendations for this department, in order to condense in public opinion, and assist the voice. The second is to actively communicate. Not only should we communicate with the network management and the propaganda department, but also communicate with the units to form a synergistic group to solve the problem. The third is to strengthen guidance. First of all, the premise of carrying out public opinion is to solve the problem, problem solving comes first, so that public opinion guidance will be effective. Second, we must be good at using the three-dimensional propaganda means to strengthen the guidance of netizen media literacy and enhance the rationality of netizen. Finally, stick to and comply with the law, and urge citizen to regulate its network words and deeds to form a powerful shock, and create a clear network environment.

\section{CONCLUSION}

To sum up, online public opinion is a double-edged sword. If properly handled, it will not only help to solve the problem, but also improve the credibility of relevant departments. On the contrary, it will not only lose the right to speak, but also bring severe challenges to the solution of things. Therefore, it is particularly important to improve the quality and strategy of leading cadres to deal with the network public opinion. In order to meet the needs of the public, leading cadres should strengthen their study, follow the law of news communication, respect the feelings of the responders and respond to the concerns of the public with an equal attitude.

\section{REFERENCES}

[1] Pan QingQuan, Wei Huimin. On the Characteristics, Influence and Effective Utilization of Network Public Opinion in Colleges and Universities [J]. Party Building and Ideological Education in Schools, 2012,(28)

[2] Li Xiaoling. Study on the Establishment and Perfection of the Basic News Spokesman System [J]. The News Spread, 2017,(10)

[3] Liu Yuqin, Li Zhen. Characteristics of Online Public Opinion on Major Epidemic and Its Management [J]. Ideological and Theoretical Education, 2020,(04) 